\title{
LOS DISPOSITIVOS ÓPTICOS Y SU RECEPCIÓN EN LA PRENSA DEL ROMANTICISMO (1835-1868). UNA APROXIMACIÓN
}

\author{
Marieta CANTOS CASENAVE \\ marieta.cantos@uca.es \\ Universidad de Cádiz
}

\begin{abstract}
Resumen
El objeto de este trabajo consiste, primero, en dar cuenta de cómo los periódicos del Romanticismo dan detalles de la aparición de estos nuevos dispositivos y de los espectáculos a que dan lugar y, segundo, en rastrear las huellas de esas novedosas experiencias, la demanda de esas nuevas máquinas e instrumentos, así como el desarrollo de las exhibiciones, de los espectáculos, en fin, de las nuevas prácticas culturales, derivadas de esa revolución iniciada en la centuria precedente, que cobran nuevo sentido a mediados del XIX y, en fin, el modo en que el lector puede vivir esa experiencia óptica de manera vicaria, es decir, por mediación del redactor del periódico.
\end{abstract}

Palabras clave: dispositivos ópticos, cultura visual, prensa del Romanticismo, diorama, panorama, daguerrotipo, fantasmagoría, mímesis, objetividad.

\begin{abstract}
The aim of this paper is, first, to account for how Romantic newspapers detail the emergence of new optical devices and the resulting shows, secondly, to trace these new visual experiences in these papers, the demand for these new gadgets and development of exhibitions, finally, the new cultural visual practices derived from the revolution started in the previous century, which charge a new meaning in the mid-nineteenth century and the way in which the reader can get optical experiences indirectly, id est through the journalist.
\end{abstract}

Keywords: optical devices, visual cultural, romantic newspapers, diorama, panorama, daguerreotype, phantasmagoria, representation, objectivity. 
Un repaso por las cabeceras de los periódicos del Romanticismo revela que buena parte de ellas se hace eco de la aparición de una serie de dispositivos ópticos y de espectáculos basados en su funcionamiento. Aunque algunos de estos instrumentos hunden sus raíces en el intento del Renacimiento de optimizar la visión, y alcanzan un grado notable de perfección en los siglos XVII y XVIII, logran sus posibilidades más notables en el XIX. La linterna mágica (1820, y 1849), El Panorama (1838), El Daguerrotipo (1841), El Mundo Nuevo (1851), El Nuevo daguerrotipo (1852), la revista peruana El Cosmorama (1867) son algunos de los más significativos, a los que podrían sumarse otros que hacen referencia a los territorios de la mirada y al sujeto de la visión como la Minerva o el Revisor General ${ }^{1}$ (1805), el Observatorio pintoresco (1837), El espectador (1841), El Reflejo (1842), El Observador (1848) y Escenas contemporáneas (1856). En esta línea y, ampliando el campo léxico-semántico, se encuentran aquellos otros que dirigen su atención hacia las artes en general, que suelen servirse de este tipo de instrumentos ópticos para mejorar su representación de la realidad, como El Artista (1833), El Museo de las familias (Barcelona, 1838), Museo de las familias (Madrid, 1843), la Iberia musical (1842), los que específicamente aluden a la pintura y sus aledaños, caso de El Museo mexicano, o Miscelánea pintoresca de amenidades curiosas e instructivas (1843), entre los que algunos, más específicamente, se refieren explícitamente a la inclusión de grabados, caso del Semanario Pintoresco Español (1836), o del Álbum pintoresco (1841), por citar algunos de los que con mayor frecuencia se hacen eco de esta nueva forma de contemplar y representar el mundo. Entre el resto de las cabeceras, aunque sus títulos no aludan claramente a estos dispositivos, cabe reseñar aquellos que dan cabida a la información sobre estos instrumentos ópticos por su utilidad para la ciencia, como el Boletín de Medicina, Cirugía y Farmacia (1839) o la Gaceta médica (1851), que informan de la invención del daguerrotipo por sus muchas utilidades y, en el caso del segundo periódico, de su uso específico para examinar diversas enfermedades, síntomas o señales, así como de aplicaciones particulares en especialidades como la Anatomía.

Por último, a los citados, conviene añadir aquellos que se sitúan en la órbita del periodismo satírico, pues no debe olvidarse que el recurso al espejo, o los anteojos, es una fórmula tradicional para ofrecer una mirada aparentemente distorsionada de la realidad y que, sin embargo, parece descubrir una verdad que se oculta tras las apariencias, algo que el tutilimundi o mundo

1. En el prospecto, se indica: «En virtud del título de Revisor general que me ha sido concedido por la sabia Minerva, recorreré y escudriñaré las costumbres públicas y la literatura; (...)» (sin paginar, pág. 2) 
nuevo, entre otros espectáculos ópticos siguen facilitando. Aquí cabría citar La Periodico-manía (1820), El Jorobado (1836), El Enano (1851), La Tarántula (1842), Gil Blas (1864). En lo que concierte a las restantes cabeceras que he incluido, si bien no ofrecen en sus títulos datos de su interés por estos nuevos dispositivos, por tratarse de periódicos de información general, de comercio, de avisos, de crítica científica y literaria, de crítica política o incluso de modas, no dejan de hacerse eco de sus avances y de los espectáculos ópticos a que el público puede acudir. De todo ello resulta que las noticias sobre estos instrumentos y las prácticas culturales derivadas de su uso atrajeron la atención de toda clase de periódicos, aunque parece que tuvieron más cabida entre los de información general y los artísticos que entre los de información científica, que solían ocuparse únicamente de ellos cuando tenían aplicaciones específicas para la ciencia.

Es cierto que en el siglo XVIII periódicos como el Memorial Literario, la Gaceta de Madrid o el Diario Pinciano, entre otros, incluyen noticias sobre el uso de estos artilugios que mejoran las posibilidades de la visión, pues es en el Siglo de las Luces cuando se produce la denominada revolución visual, surgida del progresivo deterioro de la credibilidad de la cámara oscura para conocer la realidad. En esta centuria se inicia la transformación de la forma de ver y de entender la realidad, al tiempo que, dadas las posibilidades de estos aparatos para el uso pedagógico, divulgativo y recreativo, al público de especialistas se van sumando, cada vez en mayor medida, los curiosos y aficionados que, en distinto grado, quieren participar de las nuevas experiencias y estar al tanto de las novedades (Vega 2010).

Pero, como señalaba antes, será en el siglo XIX cuando los logros de esa revolución se asienten y desarrollen con mayor amplitud. En parte, porque, para dar alas a esa revolución, era necesario un mayor avance de la prensa periódica que en el XIX se adaptaría más sutilmente a esta nueva demanda visual, al incluir grabados cada vez más «realistas», particularmente en el caso de las revistas pintorescas e ilustradas (Riego 2001). Y a lo largo del siglo la prensa permanecerá atenta a todas esas nuevas formas de captar una realidad que cambia con una rapidez inusitada para el hombre, que observa con cierta inquietud ese mundo que se le escapa y, al mismo tiempo, siente fascinación por la celeridad de una modernidad, que sin duda introduce un factor desestabilizante en el orden establecido. No obstante, ese mismo afán de exaltar las novedades fomenta la demanda, cada vez más amplia, de ese nuevo observador-espectador, que es también lector de periódicos. A medida que avanza la centuria se producirá un cambio más radical, como resultado de la captación automática de la realidad: la paulatina conversión del observador 
en espectador, productor instrumental —el hombre parece convertirse en una pieza más del dispositivo- y consumidor pasivo de una nueva cultura visual.

El objeto de este trabajo consiste, primero, en dar cuenta de cómo los periódicos del Romanticismo dan detalles de la aparición de estos nuevos dispositivos y de los espectáculos a que dan lugar y, segundo, en rastrear las huellas de esas novedosas experiencias, la demanda de esas nuevas máquinas e instrumentos, así como el desarrollo de las exhibiciones, de los espectáculos, en fin, de las nuevas prácticas culturales, derivadas de esa revolución iniciada en la centuria precedente, que cobran nuevo sentido a mediados del XIX y, en fin, el modo en que el lector puede vivir esa experiencia de manera vicaria, es decir, por mediación del redactor del periódico.

En cuanto a lo cronología y la selección de periódicos, prescindo en esta ocasión del análisis de lo que ocurre en las primeras décadas del XIX pues, si bien resulta esclarecedor para entender lo que luego va a ocurrir en plena eclosión romántica, examinar la huella de estas prácticas en esos años - y comprobar si la prensa de la época atestigua el cambio del estatuto del observador (Crary 2008) - aumentaría en exceso la extensión de este trabajo; pero no dejaré de referirme ocasionalmente a esas décadas cuando sea preciso. De todas formas, este trabajo no puede ni pretende ser exhaustivo, aunque sí trata de ser lo suficientemente representativo y significativo como para dar una idea lo más aproximada posible del reflejo que el despliegue de esta nueva cultura visual deja en la prensa (Riego 2001, Fernández 2006).

\section{Noticias periodísticas sobre la extensión y diversificación de los instrumentos ópticos}

A lo largo del XIX, se asiste al desarrollo y multiplicidad de estos dispositivos que, en principio, permiten estudiar y ampliar las posibilidades del ojo humano, y que luego, paulatinamente, y no siempre prescindiendo de su interés instructivo, se van convirtiendo en una fuente generalizada de placer estético, lo que da cuenta de la progresiva divulgación y extensión de su uso entre un público no especializado. Cabe recordar que el paso fundamental se produce cuando la cámara oscura que servía como «base objetiva de verdad visual» deja de considerarse fiable y se produce una nueva valoración de la experiencia visual, a partir de la invención de nuevos instrumentos ópticos, basados en investigaciones sobre la persistencia retiniana, la visión periférica, la visión binocular (Crary, 35), que pretenden dar cuenta de una realidad compleja y cambiante.

Para ordenar el repaso por las noticias que ofrecen los periódicos, tendré presente la clasificación de los tipos de instrumentos elaborada por Riego 
(2001, págs. 59-60) y su paulatina aparición, al hilo de las diferentes investigaciones que se iban haciendo en relación con la visión. A este respecto, de los espectáculos relacionados con la cámara oscura, distinguiré entre aquellos en: «los que la luz entra al interior (caso de los mundonuevos) o sale de dentro hacia afuera (caso de la linterna mágica) o entra y sale amplificada (como en el microscopio solar)», a los que habría que añadir la utilización en contadas ocasiones de la cámara oscura como espectáculo, la fantasmagoría, que «utiliza recursos de la linterna mágica y de la cámara oscura y también de la catóptrica o propiedades visuales de los espejos» y las sombras chinescas, «basadas en la interposición entre la luz y una pantalla de un objeto opaco que adopta una forma reconocible» y que, aunque de tradición antigua, fue reintroducido en España en el siglo XVIII.

\section{Derivados de la cámara oscura}

Las sombras chinescas

Este espectáculo de sombras se basa en la interposición entre la luz y la pantalla de un objeto opaco, que se reintroduce en España en su forma moderna a través de la figura del alemán José Brunn y su teatrito de sombras en 1779, (Varey 1972, págs. 30-31). Sin obviar su desarrollo en el siglo XVIII — del que supo sacar buen provecho Goya (Vega 2010, págs.478-479)_, es fácil encontrar el rastro de su uso en las primeras décadas del XIX, convertido a veces, tal vez por su excesiva popularidad — como recuerdan algunos testimonios-, en uno más entre otros «juguetes para señoritos».

Más tarde, ya en los años del despegue romántico, se alude a ellos no en su condición de juguete, sino de máquina, en la misma línea que la de las figuras corpóreas y, así, no es extraño encontrar el anuncio de su venta al mismo tiempo que la de estas máquinas de figuras (Diario de avisos de Madrid, 22-61835). En fechas muy próximas, Mesonero Romanos, atento desde la mirada nostálgica de su representación costumbrista, alude a ellas como metáfora del efecto que la rapidez de las mudanzas y la afición a los viajes ha producido en los miembros de su generación, convirtiéndolos en «sombras chinescas o rápidas ilusiones fantasmagóricas» (Boletín del Panorama Pintoresco, en Diario de avisos de Madrid, 16-9-1835).

\section{La linterna mágica}

Aunque conocida con anterioridad, el uso de la linterna mágica se documenta por escrito en el XVII, gracias al Ars Magna Lucis et Umbrae (1646), de Athanasio Kircher, y ya en estas fechas fue utilizada por los jesuitas para sus 
proyectos pedagógicos (Fernández 2006, pág. 81). En el XVIII despertó las reticencias de ilustrados como Jovellanos, y en los años del Romanticismo empezó a considerársele un juguete infantil que, no obstante, llegaría a convertirse en instrumento pedagógico, utilizado en las aulas a partir de la Restauración (Riego 2001, págs.67-68).

Durante el Trienio Liberal el periódico de sátira política de Justo Balanza llevó el nombre de este aparato en su cabecera, aunque fue un periódico de escasa fortuna (Fernández 2006, 275). Décadas más tarde, Ayguals de Izco funda su Linterna mágica en 1849, con intencionalidad cómica, aunque no exenta de sátira. De ella nos da una idea el artículo "Opúsculo dramático», del primer número, en que ridiculiza las pretensiones de una parte del público que acude al circo Paúl, un circo de variedades donde eran frecuentes este tipo de espectáculos ópticos. Además, el recurso a la narración del sueño del personaje del novelista francés y la intervención en el mismo de un diablo, que parece presagiarle un brillante éxito en su aventura con la manola que lo ha fascinado, son algunos de los elementos que sirven para ofrecer la mirada satírica que, lo mismo que el citado periódico, este tipo de espectáculos suele brindar. Y será ese carácter satírico el que permita atisbar entre las líneas de algunos de estos periódicos la quiebra de la imaginada unidad nacional. Pues, por el contrario, lo que caracteriza a la mayor parte de periódicos que se hacen eco de estos dispositivos y espectáculos ópticos es la de procurar una imagen que permita al lector medio y aun al de las clases populares identificarse con la idea de nación que generalmente las empresas periodísticas pretenden extender entre la nueva clase media.

\section{Fantasmagorías}

Respecto de las sombras producidas por las fantasmagorías, pueden ser consideradas como una variante de las producidas por la linterna mágica (Varey 1972, pág. 43). Eso explica que desde los primeros años del XIX la prensa hable de este tipo de representaciones artísticas, a pesar de que la difusión de la fantasmagoría del belga Etienne Gaspar Robert, conocido como Robertson, en España se produce en 1821, y de que la Real Academia no recogería su uso hasta 1832, con la acepción de «el arte de representar fantasmas mediante una ilusión óptica».

No es momento de ocuparme de los primeros aficionados a las exhibiciones fantasmagóricas, como Pinetti o Bernardino de Rueda, ni tan siquiera del creador de la fantasmagoría moderna, pero sí, en cambio, creo necesario reseñar que este tipo de espectáculos se anuncian todavía a mediados de los sesenta (Lloyd español, de 18-9-1864, p.2), aunque también es verdad que 
cada vez más su mención se documenta sobre todo en las páginas de periódicos políticos y satíricos, donde suele utilizarse en sentido metafórico; también que esto sucede en fechas tempranas como atestigua El Jorobado, donde, por ejemplo, se habla de «fantasmagoría anarquista» (19-7-1836).

\section{Mundonuevos o tutilimundis}

Se trata de una exhibición callejera, de frecuente manifestación por parte de titiriteros y otros exhibidores ambulantes. Parece que la documentación de los primeros mundonuevos madrileños data de mediados de los años 20 (Varey 1972, pág. 38), pero tras la Real Orden que determinó «que no se concediesen licencias para representar en esta corte ninguna comedia, fantasmagoría, ni función semejante, permitiéndose solo las del Tívoli, los conciertos de música vocal e instrumental y otras equivalentes», los titiriteros hubieron de arreglarse con los empresarios de los teatros para ofrecer sus funciones, y lo mismo ocurrió en otras ciudades como Zaragoza, hasta que en 1832 volvió a abrirse la mano (Varey 1972, pág. 36).

En 1851 el periódico El Mundo Nuevo traía en el grabado de su cabecera la imagen de una representación callejera en la que se observa al titiritero que, por encima del característico cajón, dirige su mirada a un público diverso, mientras con una mano toca el tambor y con la otra mueve las marionetas. El movimiento de estas aparece desdibujado a ojos del público que solo cuenta para verlos con la ayuda de la luz que penetra en el interior.

Se trata de un periódico «satírico y político literario», según reza en su cabecera, que se dirige a un público burgués, para el que sus redactores escriben indistintamente de política o literatura «porque ninguno de ellos está encargado de una sección exclusiva en el periódico» y al que ofrecen litografías y «caricaturas de actualidad» con las que, aunque no la habían ofrecido en el prospecto, piensan hacer más atractivo el periódico, de modo que El Mundo Nuevo parece querer descubrir las contradicciones y paradojas de esa actualidad española.

Panoramas, cosmoramas, teatros pintorescos y otros derivados

Todos estos espectáculos tienen en común el aprovechar «la confusión perceptiva» (Riego 2001, pág. 60). Si bien el panorama es el primero de estos instrumentos ópticos basados en una aplicación diferente de la pintura, que buscaba el efecto panóptico, es decir, que el espectador desde su posición pudiera ver el objeto - generalmente la pintura de un país o de un pueblo- por todos lados, su introducción en España es tardía, previsiblemente por las dimensiones 
y complejidad de su construcción. Así que, bastante antes de que pudiera disfrutarse de este nuevo espectáculo óptico, los madrileños solo pudieron deleitarse con las vistas que les ofrecían otros locales escénicos como el teatro de la Cruz, donde titiriteros como Cramer exhibían las «noches pintorescas y mecánicas» en 1820; luego, en la década de los 30, el profesor de hidráulica y mecánica José Ferrer construiría su propio teatro pintoresco (Varey, pág. 43).

Entretanto, los cosmoramas, una especie de mundonuevo, ofrecían mayor novedad, pues incorporaban lentes en su interior que permitían agrandar las imágenes (Riego 2001, pág. 62). Documentalmente, parece que el primer cosmorama se atestigua en 1829 (Varey 1972, pág. 43), pero la prensa nos ofrece datos más antiguos, pues, casi una década antes, el citado Robertson ya ofrecía en su gabinete, un «cosmorama o vistas ópticas» (Diario de Avisos de Madrid, de 14-8-1821, pág. 333-334).

Derivados del cosmorama serían el nietorama surgido en 1829 y el cosmoneorama, que lo haría en 1833 (Varey 1972, pág. 43). En realidad, todos ellos no son sino una sucesión de nuevos modos de intermediación entre el mundo real y el espectador, que van surgiendo a medida que se produce el desgaste de la novedad del sistema técnico usado hasta el momento o del objeto representado y, por tanto, su efectividad para producir en el espectador la ilusión de realidad (Riego 2001, pág. 54), su capacidad de provocar asombro y admiración. A veces, las novedades introducidas en el sistema de exhibición son pequeñas, como la que se menciona en el memorial que dirigen Pablo Seva, dueño de la fonda y café Cruz de Malta, y el madrileño Juan Poret, para manifestar en dicho establecimiento un cosmorama y nietorama, donde alude a una «colección de vistas de la mayor dimensión» (Varey 1972, pág. 252).

Hasta 1835 no se tendrían noticias de la intención de construir un panorama y serán precisamente los dueños del cosmorama instalado en la Galería topográfico pintoresca de Recoletos los que se planteen intentarlo. Efectivamente, el folletín de La Revista Española de 1835 y poco antes el del Eco del Comercio dan cuenta del espectáculo que ofrece la Galería topográfica inaugurada en el madrileño paseo de Recoletos, donde se combinan los resultados de los estudios de perspectiva con «las ilusiones de la Óptica» ${ }^{2}$. Se ofrecen tres vistas construidas por el director del Museo topográfico del Buen-Retiro y se reproducen varias esculturas de maestros reconocidos como Alonso Cano y José Piquer. A ello se añaden las transformaciones ópticas visibles en

2. El folletín del Eco del Comercio se refiere también a la perfección que ha alcanzado en la época «este tipo de espectáculos, en que con más o menos ilusión se intenta copiar los objetos interesantes de la naturaleza o del arte» (El Eco del Comercio, de 9-10-1835, pág. 1).

Anales, 25, 2013, pp. 105-130 
un tocador de máscaras, otras vistas ópticas, y una serie de «transparentes». La reseña de la revista añade que los socios de la galería tienen esperanza de obtener alguna ganancia para emprender la aventura de instalar un Panorama (La Revista Española, de 17 de octubre de 1835, pág. 320).

Por su parte, el folletín del Eco del Comercio advertía igualmente que, dado que la miseria general de España no permitía los desembolsos necesarios, se había adoptado «un medio si no equivalente a aquellos [los europeos] en sus portentosos resultados, no menos admirable por la exactitud, novedad y belleza que le distingue», para referirse a continuación a los que se exhibían en la citada Galería topográfico pintoresca» (El Eco del Comercio, de 9-10-1835, pág. 1).

\section{Dioramas}

Los dispositivos diorámicos «utilizan la propiedad cambiante de la luz». Consisten en una «lámina traslúcida pintada por las dos caras, que en función del juego de apertura y cierre de diversas ventanas coloreadas, permite la transformación paulatina de la imagen» (Riego, 2006, pág. 60)

Ya hacia 1826 José Gabrier construye y realiza las primeras exhibiciones del primer diorama, que fue perfeccionándose e incorporando mayor número de vistas. En la Habana se inauguró poco después un local dedicado a su exhibición, «El Diorama» en $1828^{3}$.

Años más tarde, el que tuvo mayor éxito fue el que en 1837 ofrecía la Galería Topográfica de Recoletos, para cuya iluminación había que pagar una cantidad aparte de la requerida para la entrada a la Galería (Diario de Avisos de Madrid, 23-7-1837). Este establecimiento ofrecía además tres Diaphanoramas - perspectivas transparentes_ « «el Monasterio del Escorial visto en todo su conjunto, el interior de la Iglesia de Nuestra Señora de Atocha de esta Corte y la capilla de Guillermo Tell en Suiza», que aunque de calidad, en opinión del redactor del Semanario Pintoresco Español (8-7-1838, p. 5) no pueden competir con el diorama, lo que no es óbice para que al final de su artículo alabe las cualidades del artista Blanchar y del dueño de la fábrica Platería Martínez, el coronel Pablo Cabrero.

Pero el público demandaba novedades y, si ya en 1835 El Eco del Comercio daba cuenta de algunas de las variedades que se conocían en Europa ${ }^{4}$, en 1838 el Semanario Pintoresco decide tratar de aclarar la intrincada red nominal con

3. «Teatro», en Diccionario de la Literatura Cubana, Editorial Letras Cubanas, 1980.

4. Efectivamente, el periódico hablaba de Panorama, Diorama, Neorama, Georama y Cosmorama (El Eco del Comercio, de 9-10-1835, pág. 1) 
la que se designan estos nuevos espectáculos (Riego 2001, pág. 54). Efectivamente, en un artículo dedicado al nuevo Diorama que se exhibía en la Alameda junto a la antigua platería de Martínez, recurriendo a su etimología, el redactor trata de explicar las diferencias entre el panorama, cosmorama, panstereorama — galería topográfica en relieve-, el Alporama —vistas de los Alpes-, el Cosmo-mecánico - espectáculo de física experimental y fantasmagoría-, el Diaphanorama — vistas transparentes de sitios pintorescos-, Pyrrorrama - vidrios transparentes, con un mecanismo de música singular-, el Diorama, el Uranorama - movimiento de todos los cuerpos celestes-, Europorama — vistas de Europa—, el Georama — «esfera colosal de más de cien pies, en que estaban representadas todas las partes del mundo y a que se daba vuelta por una galería circular»-, el Neorama — vista del interior de un templo—, y añadía: «Hay además el Peristrephorama, el Autorama y el Ciclorama, (que no son más que panoramas móviles) y otros infinitos nombres tan exóticos como los ya dichos». De modo que es fácil concluir que, salvo algunas diferencias en la utilización de mecanismos de movimiento o de incorporación de la música, las coincidencias son mayores y su variedad radica no tanto en la técnica, excepción hecha de las que distinguen al panorama y al diorama, como en los distintos objetos que representan (Semanario Pintoresco Español, de 8-7-1838, p. 5).

\section{El daguerrotipo}

Invención moderna datada en 1839, la novedad del daguerrotipo radica en permitir, frente a otros intentos anteriores, la captación automática de la realidad. Entre los periódicos de esta época, uno de los primeros en divulgar conocimientos relativos a las investigaciones ópticas fue El Instructor, o Repertorio de Historia, Bellas Letras y Artes, una publicación mensual que, dirigido al mundo de habla hispana, comenzó a publicar en enero de 1834 la editorial londinense de Ackermann \& Co. Después de haberse ocupado de instruir a sus lectores sobre el sentido de la vista y las leyes de la visión ${ }^{5}$, incluyó entre sus páginas descripciones sobre la linterna mágica, el dibujo fotogénico y el daguerrotipo ${ }^{6}$.

5. A este propósito, publica «El mecanismo del ojo para formar las imágenes y trasmitirlas al alma es una de las mayores maravillas de la naturaleza, y la feliz invención de las lentes ópticas nos ha hecho capaces de averiguar las leyes de la visión», a continuación explica «la acción de la luz en los ojos» y la formación de las imágenes en la retina ( $E l$ Instructor, o Repertorio de Historia, Bellas Letras y Artes no 30, 1836, p. 177, 182).

6. En el número 31, El Instructor se dedicaba a discurrir sobre los movimientos del ojo, las diferencias fisiológicas según el sexo y la raza, así como un examen sobre las expresiones 
En el $\mathrm{n}^{\circ} 73$, de enero de 1840, bajo el título «Heliografía o Daguerreotipo», El Instructor ofrece una completa descripción de esta invención. Comienza por desgranar algunos extractos del informe de Françoise Arago a la Cámara de Diputados de Francia, para detallar a continuación las cinco operaciones que permiten concluir con éxito una sesión de daguerrotipia. Otros periódicos como El Guardia Nacional y el Diario Constitucional de Palma publican artículos sobre el invento de Daguerre en ese mismo mes de enero y el Eco del Comercio incluye al mes siguiente una noticia de Palma de Mallorca en la que «los amantes de las Bellas Artes» de la ciudad habían conseguido, mediante suscripción, hacerse con un daguerrotipo que, después de haber permitido obtener algunas vistas de la parte septentrional de la isla, «dignas de formar una colección de países», sería regalado «al instituto balear para aumento de su gabinete de química» (29-2-1840, p. 2130). Por su parte, en el folletín de El Constitucional de Barcelona de 11 de febrero, dentro del informe de actividades de la Academia de Ciencias Naturales y Artes de Barcelona, se advertía de la construcción de uno de estos aparatos que podía ser el primero en España (pp.1-3). En realidad, este periódico ya había incluido el año anterior una noticia sobre el uso de este invento entre los espectáculos callejeros, con una curiosa advertencia:

Mañana domingo, 10 del corriente, a las once, si el tiempo lo permite, se sacará la vista de la Lonja y de la manzana de casa Xifré, por el nuevo método del Daguerrotipo, desde el terrado del primer piso de las casas situadas frente de la de Xifré.-Para el buen éxito de la operación, conviene que los espectadores que se hallen en los balcones y ventanas de la Lonja y de la citada casa de Xifré se retiren durante los pocos minutos que la plancha estará expuesta al foco de la cámara oscura.

Se ruega, pues a dichos espectadores, que se retiren al oír un primer fusilazo, pudiendo volver a sus puestos luego que oigan el segundo. La exactitud de la operación es tal, que si algún espectador se desentiende de este ruego, quedará indeleblemente marcada en la plancha la prueba de su indocilidad ( $E l$ Constitucional de 10-11-1839, pág. 3).

A finales del año 1840 El Instructor incluye el artículo el «Daguerreotipo o Miniaturas Fotográficas», donde se informa de la patente del norteamericano Alejandro S. Wolcott, que reemplazó la lente del daguerrotipo por un espejo cóncavo, a fin de obtener daguerrotipos más pequeños, «miniatura de $3 / 8$ de pulgada» ( $\mathrm{n}^{\circ} 84$, diciembre de 1840, p. 374). Poco antes el Guardia Nacional

del ojo. Más tarde, en el correspondiente al mes de octubre inserta una «Historia de los Observatorios» (El Instructor, o Repertorio de Historia, Bellas Letras y Artes no 30, 1836, p. 296-300) entre ellos el de Madrid, del que inserta un grabado, al que acompaña otro del telescopio de Herschell. 
informaba de otras mejoras introducidas por el Dr. Donné y del propio Daguerre para reproducir las imágenes del daguerrotipo (13-11-1839), así como las operadas por el académico Mr. Seguie para disminuir su tamaño y facilitar su uso (27-11-1839).

Los espectáculos pronto se hacen eco de estas ventajas y así, aprovechando las invenciones de Daguerre, el cosmorama de la madrileña calle Ancha de Peligros ofrece vistas de Lisboa, así como de Gibraltar y de Mesina, realizadas mediante la técnica del daguerrotipo (El Observador 25-10-1849). Lo mismo ocurre en otros locales de la capital, pero sería imposible dar cuenta en tan breve espacio de todos ellos.

Por el contrario, dada su continua referencia a ellas, sí considero necesario indicar que para estas fechas se había puesto de moda incluir ciertas técnicas, como la que se denominan «cuadros disolventes», es decir, la proyección de placas que, al ser sustituidas gradualmente, logran simular cierta sensación de movimiento. En Madrid, existía un local específico para proyectar imágenes con esta técnica, pero la llegada a España de Mr. Laschott desde teatros parisinos, donde había sido ampliamente elogiado por la prensa, volvió a poner el foco en este tipo de espectáculos del que dan cuenta El Popular (7-4-1849) y El Heraldo (27-9-1849). Es más, aunque el redactor de El Áncora observa su relación con otros espectáculos más antiguos, parece que su calidad supera cualquier comparación: «Los cuadros disolventes de Mr. Laschott corresponden a los espectáculos de fantasmagoría, que bajo diferentes colores hemos visto ya en esta capital» y añadía «Algunos de ellos están muy bien pintados, realzando sus vivos colores la luz que emplea el autor. Algunas bellas combinaciones, producen buena ilusión y merecieron aplauso» (24-6-1852). Dos días después, el mismo periódico detallaba el programa ${ }^{7}$.

También el popular Circo de Paúl en su «suaré recreativa» del 7 de septiembre incluía, entre otros atractivos, «los cuadros disolventes; los fenómenos eléctricos; la fantasmagoría animada; el autómata volteador» (Diario de Avisos de Madrid, 7-9-1852).

7. (Primera parte),$-1^{\circ}$. Las minas de Balbec (nuevo). 2. ${ }^{\circ}$ Una capilla en Sierra Morena, 3. ${ }^{\circ}$ La roca de Thun-thin-Than en China. $4 .^{\circ}$ Vista del molino de Gulknstein en Suiza en la que se verá el mágico y sorprendente efecto del movimiento de las nubes, ocultando unas veces a la luna para dejarla después más brillante a la vista de los espectadores, y también con la sorprendente vista de la nieve. $5 .^{\circ}$ Gran iluminación del canal móvil, en China. $6 .^{\circ}$ La hermosa catedral de Milán. $7 .^{\circ}$ Vista de Zurich en Suiza con los correspondientes efectos de la luna..$^{\circ}$ Interior de la capilla de Ntra. Señora en Jerusalen. (Segunda parte). 9. ${ }^{\circ}$ Interior del palacio del Dux en Venecia. 10 ${ }^{\circ}$. La capilla real de Dublin. Finalizando con los lindísimos juegos Chromatopes y la fuente de M. Laschott. 


\section{El estereoscopio y el caleidoscopio}

En el caso de estos dos instrumentos, el estereoscopio surge como resultado de las investigaciones de la visión binocular mientras el segundo no es sino el fruto de la transformación y modernización del clásico caleidoscopio que, como espectáculo, suele consistir en una proyección de gran tamaño (Garófano, 2007, 244) $)^{8}$. Estos nuevos dispositivos ópticos, que pronto dan origen a nuevos espectáculos deberían haber ocasionado algún tipo de dislocación en el concepto de realidad, que tenían hasta entonces sus contemporáneos, tal como señalan otros testimonios europeos (Crary 2008). Sin embargo, lo primero que provocan es mera curiosidad científica, tal como recoge El Instructor de 1839, donde al hacerse eco de las actividades de la «Asociación Británica para el adelantamiento de las Ciencias» habla por primera vez del estereóscopo (El Instructor, o Repertorio de Historia, Bellas Letras y Artes $\mathrm{n}^{\mathrm{o}}$ 61, 1839 , p. 14 y ss.). De la reseña de las memorias leídas en la sesión de aquel año, destaca por su novedad la exposición sobre la «visión binocular», en la que el profesor Wheatstone continuaba la disertación ofrecida el año anterior, pero ofreciendo la aplicación práctica de dicha teoría sobre un instrumento de su invención, el stereoscope. Este dispositivo tenía la propiedad de «presentar a la mente la perfecta semejanza de los objetos sólidos» y ello porque gracias a la visión conjunta que el stereoscopio ofrecía de las dos imágenes desemejantes que se presentaban a cada ojo, podía contemplarse el objeto no de forma plana, sino en relieve. El editor concluía: «La ilusión es tan perfecta, que ningún esfuerzo de la imaginación puede persuadir al observador que es una pintura en un plano» (El Instructor, o Repertorio de Historia, Bellas Letras y Artes $\mathrm{n}^{\circ} 61$, 1839, pág. 18). El mismo periódico dedicará su número de junio a explicar con mayor detalle el funcionamiento del «Estereoscopio o visión binocular» ( $\mathrm{n}^{\circ}$ 66, 1839, pág. 173-175), a partir del libro Contribuciones a la fisiología de la visión, del propio Wheatstone.

A pesar de estas primeras noticias, habrá que esperar hasta la década de los 50 para encontrar reseñas más amplias sobre este instrumento, pues solo a partir de esa fecha empezó a generalizarse su uso en Europa y en Norteamérica (Crary, 2008, p. 157). La primera que he localizado se recoge en $\mathrm{La}$ España y hace referencia a otra noticia inserta en un periódico de Cádiz, sobre retratos estereoscópicos, que no he logrado localizar:

8. Rafael Garófano, que se ha ocupado de estudiar el caso gaditano, utiliza acertadamente la prensa local, sin dejar de acudir a otras fuentes. Cf., Los espectáculos visuales del siglo XIX. El Pre-Cine en Cádiz, Cádiz, Quorum editores, 2007. 
Hemos tenido ocasión de admirar esta clase de retratos en el gabinete de la calle del Veedor número 58 1/2, la cual es la mejor aplicación que se ha hecho del daguerrotipo desde su invención.

El estereóscopo es un pequeño aparato de óptica en el cual se ponen dos retratos de una misma persona hechos con las proporciones y reglas necesarias, y por una combinación de óptica se reúnen en uno solo representando la persona con el relieve natural. (...) Los retratos que se hacen en el expresado gabinete, son, en el concepto de muchos inteligentes, de lo más acabado, como puede verse en las muestras que están de manifiesto en la calle Ancha. El estereóscopo puede verse en casa de los retratistas (La España, de 20 de julio de 1852).

Pudiera deberse al retratista Victor Cassiens que, al menos desde el 11 de julio de 1850, anuncia haberse trasladado al $n^{\circ} 58$ de la calle Veedor y ofrecer «miniaturas fotográficas», con métodos adquiridos en París y cuyos fruto se exhibe en la calle Ancha, en el despacho de don Hipólito Tremblay (El Comercio, 31 de julio de 1850).

Con idéntico recurso al relato testimonial de la primera persona, al año siguiente, un periódico de Barcelona describe con mayor detalle el invento:

Hemos tenido ocasión de ver en el acreditado establecimiento de instrumentos ópticos del Sr. Dalmau un poliesteróscopo binocular cuyos objetos producen en efecto una completa ilusión. Verdaderamente el estereóscopo es uno de los instrumentos mágicos de la ciencia y de la industria moderna. Consiste simplemente en una caja de medianas proporciones provista en uno de sus lados de dos tubos de anteojo que exigen la aplicación de ambos ojos.

Colocados en el fondo de la caja ya iluminada con luz natural o artificial, una pintura doble, un dibujo, una miniatura ó una figura geométrica también doble, se ven por los dos ojos al mismo tiempo por medio de los dos tubos adaptados a la caja (El Áncora, de 20-9-1853, pág. 1300).

Y a partir de este nuevo dispositivo, surge pronto el espectáculo. Al día siguiente el mismo periódico, entre las diversiones públicas habla ahora del poli-estereoscopo de Dalmau que se exhibe en la Rambla, como una adaptación del «estereoscopio ordinario», al que él "por medio de un sencillo mecanismo ha conseguido dar a sus bellísimos cuadros la animación de colorido de que carecen los monótonos cuadros sacados con el daguerrotipo» produciendo «varios efectos de luz, imitando las diferentes variaciones atmosféricas del día y la noche» (El Áncora, de 21-9-1853, pág. 1328).

A la altura de 1857, ya se lo relaciona con la fotografía y, bajo el epígrafe de «Trabajos fotográficos», se alaba los progresos realizados en este arte, al tiempo que se comenta la afición al estereóscopo entre las familias londinenses, en las que se ha convertido en un artículo de moda con el que pasar la noche «admirando sus maravillas» (La España, 24-1-1857). Muy pronto adquirirá 
en España esta condición de objeto de consumo y con este motivo La Iberia lo incluye en su sección de anuncios en el mes de marzo, mientras La América lo hará en el mes de septiembre. De la afición a este aparato da cuenta indirecta una gacetilla de La España, de 28 de abril de 1858, que recoge cómo una mujer había perdido su dinero cuando un ratero se lo sacó del bolsillo mientras miraba distraída "varias fotografías a través de un estereóscopo».

Para enero de 1859, El Clamor público anunciaba su venta por suscripción, lo que da idea de cómo este instrumento se había hecho popular:

contando con las mejores fábricas de Paris y Londres, se abre suscripción a una bonita caja con seis vistas de lo mas escogido y un buen estereóscopo de caoba a prismas, renovándose las vistas los sábados de cada semana; todo por la única cantidad de 8 rs. mensuales (8-1-1859).

Lo mismo hacía el Diario de Avisos, que indicaba que se servían a domicilio (10-1-1859) ${ }^{9}$. Precisamente, el interés por ese «instrumento mágico, maravilloso», que salido «del gabinete del físico, ha obtenido el derecho de ciudadanía en todos los salones», estimulaba a los editores de El Mundo Pintoresco a insertar un artículo sobre la «Estereoscopia» donde explicaba la «visualidad binocular» de Wheatstone, al tiempo que reseñaba varios experimentos caseros que se podían realizar para comprobar dicha teoría. A la descripción del estereóscopo de Wheatstone, seguía el detalle de las mejoras introducidas por Brewster y Julio Dubosk, Claudet, D’Almeida y finalmente se lamentaba de que algunos lo consideraran un simple juguete $\mathrm{u}$ objeto de entretenimiento (6-2-1859, pp. 47-48). Otro periódico madrileño, El Museo Universal, recordaba que se había convertido en distracción obligada de las familias en las tertulias de las noches de invierno ( 25 de noviembre de 1860), aunque iba más allá al explicar su funcionamiento y exponer las diferencias que se producían según la distancia a la que se colocara el objeto contemplado, o lo que ocurría cuando se contemplaban dos mitades de un mismo objeto o las imágenes de dos objetos diferentes. Dos años después, El Panorama Universal incluía otro artículo similar debido a M. M. F. que alababa las perspectivas que se abrían al aplicar el estereóscopo a la fotografía (28-9-1862, págs. 309-310). En todo caso, vale la pena apuntar que este instrumento se había incorporado a los espectáculos con alguna novedad como el tamaño del «gran esteróscopo redondo», que era uno de los atractivos del programa que se exhibía en «El Gran Ciclorama Universal» en Madrid (Diario de Avisos de Madrid, 6-1-1861).

9. En 1866 la venta de vistas para estereóscopo de toda Europa se anuncia en un taller de fotografía (La Soberanía Nacional, 7-4-1866). 
Años más tarde, se puede rastrear en la prensa la aparición del moderno caleidoscopio, que, mediante un pequeño mecanismo, permitía la aparición «de muchas figuras vistosas y simétricas». Su novedad lo convirtió en «juguete del año» de los salones parisinos y es que, a pesar de que en lo fundamental su artificio se basaba en el del clásico instrumento, perfeccionado y transformado, tenía el atractivo de «la sátira y la actualidad», al permitir distorsionar las imágenes de personajes del momento (La Época, 28-12-1868, p. 6451). Pronto el disfrute del moderno caleidoscopio se incorpora a la vida cotidiana de los españoles y el Diccionario de la Real Academia admitiría su uso en la edición de 1869 (Frutos 2010, p. 113).

Desde luego que la óptica seguiría avanzando y con ella el desarrollo de diferentes instrumentos para captar la realidad de forma automática. Algunos de ellos como la aparición de la instantánea en 1881 traerían nuevas formas de mirar (Fernández 2006, pág. 369), pero su análisis queda fuera de los límites de este trabajo, así que me interesa dirigir ahora la atención al receptor.

\section{Del observador-espectador y del lector}

Vista, pues, la información que recaban los periódicos sobre la aparición de estos dispositivos, su funcionamiento y la deriva en atractivos espectáculos, así como su introducción en España, llega el momento de examinar los datos que ofrece la prensa sobre el tipo de público que asistía a estos espectáculos y lo que de su experiencia visual recogen los periódicos, principalmente lo referido al placer estético, derivado de una ilusión de realidad (Villanueva 1992), que se va renovando con cada uno de los nuevos dispositivos ópticos. A este respecto me interesa descubrir la posible experiencia vicaria del lector, pues de alguna manera, a través de las noticias y comentarios de los periódicos, al lector se le propone una «vivencia por delegación», que le permite atisbar o intuir, al menos, estas nuevas prácticas visuales. En este sentido, conviene tener en cuenta que, si el éxito de las sombras, de las primeras fantasmagorías, el mundo nuevo o la linterna mágica, se debieron en buena medida a la capacidad retórica del titiritero o exhibidor, puede decirse que, en la crítica de las nuevas experiencias visuales, el arte persuasivo con que el redactor del periódico comenta el espectáculo además de sustituir o, en su caso complementar, al gancho del charlatán o del exhibidor que tenía como público mayoritario a las clases populares, con su capacidad persuasiva puede incidir en el deseo del lector de conocer por sí mismo la novedad de la que el periódico se hace eco, provocando su deseo de convertirse en espectador por influjo de la experiencia previa del periodista e incluso, como decía, que la «viva» a través de la lectura. 
De todas formas, al analizar la huella del disfrute de estos dispositivos visuales, parto de la idea de que lo que cuentan estos periódicos está destinado a conformar una imagen nacional (Fernández 2006, 270), de la que quieren hacer partícipe a un público burgués, pero de la que pretenden que no quede excluida la clase popular (Riego 2001, 125), con lo que el comentario de los espectáculos se hará en esta dirección. La paradoja puede estar en que muchos de esos periódicos, desde su propio título «pintoresco», parecen dudar entre conformar una mirada nostálgica hacia el pasado - apenas entrevisto por la cámara oscura o la linterna mágica - o dejarse alumbrar por la novedad y maravilla del presente, que captan estos nuevos dispositivos, sin cuestionarlo.

Pues bien, como he indicado antes, la novedad de la técnica afecta a varios aspectos que tienen que ver con la ilusión de realidad, de verdad, que es la principal fuente de placer estético del espectador, pero esta experiencia también viene condicionada por el lugar desde el que contempla el objeto representado, las condiciones lumínicas, su condición de observador activo o espectador y, en su caso, la persuasiva de su traslación al lector.

Se puede comprobar lo que digo al leer la reseña que hace el Eco del Comercio de los espectáculos ofrecidos por el panorama y el diorama en la fábrica de la Platería Martínez. El periodista, además de destacar su novedad, porque no intervenían los cristales ópticos y la luz artificial como en otros espectáculos más antiguos, alaba la habilidad artística de las pinturas «combinando con admirable ingenio la luz natural por medio de transparentes», hasta conseguir «una ilusión tan perfecta en la dimensión, forma y detalles de los objetos reproducidos, que solo puede encarecerse diciendo que es absolutamente la verdad» (El Eco del Comercio, de 9-10-1835, pág. 1). Es decir, a pesar de que en ocasiones como la que acabo de mencionar, la descripción del funcionamiento de estos espectáculos pueda dejar al descubierto los secretos de la técnica, la retórica persuasiva tiende a destacar la ilusión de realidad que vive el público para fomentar la demanda de este tipo de espectáculos visuales.

Claro que no siempre ocurre así y a veces la prensa ofrece reseñas más distanciadas, como con alguna frecuencia sucede en el Semanario Pintoresco. Así, en uno de los artículos que trata sobre el panorama, a pesar de la alabanza que encierra la crónica, el redactor traslada al papel su esfuerzo por no suspender su facultad crítica, su capacidad de duda:

Es sorprendente la ilusión que causa el efecto del panorama artificial, ninguna ilusión de óptica lo iguala hasta ahora, se confunde con el original mismo siempre que los objetos sean inmóviles: es preciso hacer reflexión para no engañarse que se está dentro de un edificio, tal es la fascinación de nuestra vista (Semanario Pintoresco Español, de 6 de agosto de 1837, pág. 243). 
Al año siguiente, otra crónica del mismo periódico en esta ocasión referida a un espectáculo diorámico, procede del mismo modo, pues, a pesar de considerar que el diorama es la perfección y complemento de todos ellos por «la magnitud de las copias, la minuciosa exactitud en los detalles, y la armoniosa combinación de la luz natural», que llevado a la representación del interior de un templo (neorama), «nada deja que desear a la imaginación», el redactor aclara que «en vez de violentarse para dejarse llevar de la ilusión tiene que trabajar para persuadirse de que lo que mira no es verdad». Esta confusión que lleva a identificar la imagen con la verdad es lo que destaca del neorama del templo del Escorial, cuyo mérito artístico es comparable — asegura- al diorama de Londres o al de París (Semanario Pintoresco Español, de 8-7-1838, p. 5).

Unos días más tarde, otra revista, El Panorama, incluye ahora un comentario negativo del diorama del Escorial:

El Diorama, fundado por el Sr. C. hace furor; sin embargo, no somos nosotros de los más enfurecidos por el susodicho espectáculo que aquí para inter nos pudiera salirse del monasterio del Escorial y amenizar un si es no es las vistas que presenta. Bastante tristes nos tienen los suicidios para venirnos ahora recreando los ojos con panteones (El Panorama, de 26-7-1838, n. ${ }^{\circ} 18$ ).

No es lo más frecuente, insisto, aunque quizás en este caso parece que el ánimo fúnebre del redactor es el que acentúa la tristeza de las vistas del diorama que representan al monasterio. De hecho, la tónica suele ser la contraria, que el redactor, lo mismo que el espectador, se rinda ante la maravillosa -aunque solo sea por lo desacostumbrada - visión que contempla. En todo caso, junto con el que he comentado más arriba, inserto en el Semanario Pintores$c o$, es uno de los pocos testimonios en que el espectador no está dispuesto a acatar la norma, que parece obligar a la rendida admiración ante este tipo de espectáculos.

Del diorama de París, que parece convertirse en el referente fundamental de estos periodistas, ofrece un testimonio de primera mano el periódico barcelonés El Museo de las familias, una publicación que contaba ya con 3.000 suscriptores, según indican los editores en su presentación del tomo II (1 de mayo de 1839), y que, desde sus comienzos aspiraba a encontrar entre su público lector al jornalero, al «muchacho aprendiz», «la soltera, la casada, la madre de familia, el comerciante, el labrador, el artesano, el marino», y «sobre todo la niñez», para ofrecerles, en la estela de la tradición ilustrada enciclopédica, información sobre todo tipo de conocimientos (Riego 2001, págs. 115-117), tratando de conformar una imagen universal para todo su público.

Para este amplio abanico de lectores inserta la comunicación dirigida desde París por su paisano - y de ello se complacen los editores-, Felipe 
Monlau, a la Academia de Ciencias de Barcelona, donde además de informar sobre el daguerrotipo, incluye noticias de la trayectoria de Daguerre, pues su invención del diorama había procurado notable atractivo a los espectáculos de París.

Monlau, que poco antes ha explicado el daguerrotipo utilizando una analogía con respecto al ojo, considerándolo como cámara oscura, siente ahora la necesidad de recordar el efecto de este increíble «espectáculo óptico», el diorama de Daguerre. Para ello, en primer lugar indica la disposición del escenario, de las tres vistas de gran escala al fondo del mismo, y de los espectadores sentados «en los bancos del anfiteatro que corre delante de cada cuadro, y a mediana distancia».

Detalla luego las sensaciones que como espectador recibe ante cada cuadro, el primero de ellos el terremoto del valle suizo de Goldau en 1806: «Al sentarse el espectador, experimenta la más agradable sensación: el valle está tranquilo, brillante y risueño como un verdadero paisaje de Suiza». Inmediatamente detalla los cambios de luz que pueden contemplarse, pero haciendo hincapié en la visión subjetiva del observador, que se desprende del adjetivo «siniestro» y que prepara al receptor para el efecto de la catástrofe: «Gradualmente se va apagando la luz; un siniestro crepúsculo sucede a los torrentes de claridad que poco antes deleitaban la vista; y por último, al pálido reflejo de la luna, asiste el espectador a una escena de devastación». A continuación, Monlau explica la dinámica del instrumento insistiendo en su efecto artístico:

El cuadro es siempre el mismo; el espectador no se ha movido: estas trasformaciones mágicas sobre un mismo lienzo son debidas tan solo a la descomposición de la luz que da en el cuadro, y que Mr. Daguerre sabe modificar con arte exquisito. (El Museo de las familias, nº 2, 1839, p. 466).

Con igual entusiasmo, Monlau describe seguidamente la visión de la inauguración del templo de Salomón, así como las sensaciones recibidas al contemplar la predicación de un sermón en la iglesia de Santa María Nova de Monreale en Sicilia (Riego 2001, p. 93). Para terminar, Monlau destaca la fidelidad que consiguen las representaciones realizadas mediante el daguerrotipo y la facilidad con que gracias a él los retratistas podrán «fijar» las figuras de sus modelos (El Museo de las familias, $n^{\circ} 2,1839$, p. 467). En este sentido, conviene destacar que la impresión que obtiene el espectador de las fotografías hechas al daguerrotipo es la de contener un sustituto de la realidad (Riego 2001, p. 300).

En esa misma idea incide otro periódico, al explicar la novedad del daguerrotipo y su capacidad de «fijar casi instantáneamente esta imagen en el papel que la recibe», para alabar luego el efecto de realidad que produce: 
«Cualquiera vista, un paisaje, un retrato se trasladan en pocos minutos, sin auxilio de la mano del artista y con una verdad (exceptuando el colorido) a que no podría llegar el arte (...)» (El Panorama, de 4-7-1839, n. ${ }^{\circ} 27$ ).

Con todo ello, a pesar de que pueda dar la impresión de que unos espectáculos van siendo sustituidos por otros en función de su novedad, el hecho es que sin dejar de ser cierto, muchos de ellos conviven a la vez, a veces pasando de unos locales más selectos a otros más populares, en otras ocasiones introduciendo pequeños cambios que permiten que viejos y nuevos espectáculos se complementen, de modo que al llegar la mitad de la centuria la oferta es muy amplia, como señala El Observador, al dar noticia de la cifra «de teatros y otras diversiones públicas que Madrid cuenta». En opinión de este periódico, su número «da idea de cuánto se ha aumentado en todas las clases la afición a este género de espectáculos» y relaciona esta diversificación y popularidad con el incremento poblacional que soporta la ciudad: «Este desarrollo que se nota en la afición a las diversiones teatrales es también una señal del grande aumento que cada día se experimenta en la población de la capital».

Más adelante, después de añadir el listado de locales $^{10}$, comenta, admirado, cómo es posible que haya público para tantos espectáculos y para tan numerosas funciones:

Durante los días de Pascua y fiestas siguientes, todos los teatros, menos el Real, han dado dos funciones diarias, y todas han estado sumamente concurridas. En los salones de exposición de vistas, gabinetes recreativos y demás de este género ha habido tres y cuatro entradas cada día, y en todas ha sido grande la concurrencia.

Además, en la Plaza de toros se han dado dos o tres funciones de novillos, y en el Hipódromo de la puerta de Santa Bárbara otras tres o cuatro ejercicios gimnásticos, de cuerda, juegos icarios y demás que en aquel lugar se acostumbra (El Observador. 2-1-1851, n 852).

El concurso de toda clase de público y el hecho de que algunos de estos números tuvieran que manifestarse entre «tinieblas» provoca algún que otro jaleo o «zambra», como lo llama el cronista de El Clamor público (25-8-1852), donde se halla ocasión, como señala con disgusto el redactor, de que algún «mozalbete» se propase con una joven, lo que, más allá de la cuestión de

10. La relación que ofrece es la siguiente:

Teatro Real. - Teatro Español. - Teatro del Drama. - Teatro de la Comedia. - Teatro de Variedades. - Teatro del Circo. - Teatro de la Cruz. - Circo Ecuestre. - Teatro del Numen. - Teatro de Buenavista. - Teatro de Leganitos. - Teatro del Genio. - Salón de la Calle del Amor de Dios. - Salón de la Calle de Capellanes. - Templo de la ilusión. - Galería topográfica. - Diorama. - Panorama. - Viaje por el mundo a pie quieto. Gabinetes recreativos y exposición de vistas en las calles de Peligros. 
orden público, perjudica la contemplación de los cuadros disolventes que se exhiben en el circo Paúl. Si bien, estas noticias sobre eventuales altercados no empañan el mérito de la generalidad de los espectáculos y menos aún los que se exhiben en otro tipo de salas, particularmente los más novedosos, en los que una y otra vez su capacidad para provocar la ilusión de verdad es lo más reseñable.

Entre estas invenciones, la visión de las imágenes generadas a través del estereoscopio es una de las más aclamadas, al menos al principio, por su ilusión de realidad, como recoge La España de un periódico de Cádiz, en una notica a la que me he referido líneas atrás: «El parecido que se ve en el estereóscopo es tan sorprendente, que no parece sino que se está mirando la misma persona, a la cual no le falta más que el movimiento» (La España, de 20 de julio de 1852).

La misma admiración ante el efecto mágico que sobrecoge al observador se halla en El Ancora:

Entonces por un efecto verdaderamente maravilloso, por una ilusión irresistible y una convicción completa de sensación, el dibujo adquiere el relieve y la pintura se convierte en escultura (20-9-1853).

Unos años más tarde La España explica las novedades introducidas en este aparato, a fin de atrapar con mayor eficacia la imaginación del espectador y transmitirle la necesaria ilusión de realidad:

Las mejoras realizadas por M. J. Duboseg en el estereóscopo, han perfeccionado tan precioso instrumento hasta el punto de poderse ver en relieve las imágenes fotográficas de mayor tamaño. Con el auxilio de prismas rectangulares que giran variando la inclinación de sus lados para adaptarlos a todas las vistas y de lentes biconvexos, ha llegado el señor Duboseg a corregir todos los defectos de que adolecían los estereóscopos antiguos. Es de esperar que muy pronto se harán retratos de tamaño natural que equivaldrán a tener la persona retratada a la vista (12-2-1857).

Mayor tamaño, reproducción del movimiento, son cualidades que los periódicos prevén en un futuro próximo, pues sus creadores —aseguran- están ya en el momento presente indagando sobre esas posibilidades.

En fin, las ventajas de este dispositivo, con respecto de la verosimilitud que se logra mediante la pintura, se convierten en otro tópico que reproduce El Clamor público:

En vista de los grandes adelantos que ha alcanzado la fotografía para que todas las personas curiosas puedan ver en el estereóscopo los principales países del mundo, sus columbres, monumentos y los paisajes más pintorescos, con la verdad que le presta el estereóscopo, y que el pincel apenas podría describir (8-1-1859). 
Mientras, las novedades y adelantos de cada uno de esos inventos van haciéndose cotidianas, hasta el punto de que del sentido recto se pasa con facilidad al metafórico, como hacen algunos escritores políticos al hablar de «estereoscopio moral» (El Clamor Público, 25-8-1859) ${ }^{11}$.

Poco después, el éxito de ventas obtenido por la Compañía Estereoscópica de Londres en la Exposición Universal de 1862, ampliaría su fama y, con ella las ventajas del estereóscopo recorren toda la literatura (Fernández 2006, págs. 113-114). Por ejemplo, el protagonista del Viaje de Sir Edmundo Broomley en busca de una taza de té, que publicaba La Moda Elegante, asevera entusiasmado: «Yo quiero dar al mundo una China estereoscópica que cabrá entera en un bolsillo de la dimensión ordinaria» (5-7-1863, p. 215).

Algunos años después, el protagonista de «El carnaval sin careta», de Julio Nombela, convierte la imagen recién advertida de una mujer «en el cristal de un sorprendente estereóscopo» (La Época, 5-3-1867, n 5893, s.p., pág. 3). Y, en fechas próximas, Antonio Flores en sus Misterios de Madrid incluye otra imagen similar: «La mujer es para el hombre, niño siempre, y sobre todo cuando se trata de ellas, un juguete complicado, las vistas de un estereóscopo por ejemplo» (La Época, 4-6-1868, pág. 6283).

También en la crítica literaria se extendió su uso retórico, como se advierte en el comentario de Aureliano Fernández-Guerra sobre El Quijote, que inserta la Revista Ibérica:

Tienen pues a mi juicio razón sobrada los que sospechan, que en este libro se halla encubierta una fina sátira de aquel siglo, y le estiman su clarísimo espejo y de la humanidad juntamente, que es siempre y en todas partes la misma, en fin, los que le aprecian colección magnífica de perspectivas para estereoscopio, y de retratos de cuerpo entero de personas de todos estados, gustos y condiciones, hecha delante de los propios originales por el mayor pintor del mundo. Digo el mayor, porque no sólo fotografiaba las líneas y colores, la luz y las sombras, y el bulto deleitable en lo exterior de las perspectivas y de la figura humana, sino lo íntimo y secreto, los erráticos afectos del ánimo, el movimiento que es la vida, el alma que es el soplo de Dios. (Revista Ibérica de ciencias, política, literatura, artes e instrucción pública, 1-4-1863, pp. 397-398).

Algo similar sucede en la reseña de la obra del costumbrista Antonio Flores, Ayer, hoy y mañana, que La Violeta introduce en los siguientes términos:

11. También la revista satírica El Moro Muza incluía en «Un matrimonio feliz» la reproducción de los cuadros de cada uno de los cónyuges a que da título el artículo, acompañados de otro resultante de ser retratados conjuntamente por el estereóscopo (3-6-1860, p. 268). 
Examinada con el estereóscopo de la razón la última obra del Sr. Flores, Ayer, hoy y mañana, resulta ser una fotografía precisa de tres generaciones encastilladas en un siglo, la una pacífica y feliz, sin deseos y sin ambición; la otra inquieta y turbulenta, con aspiraciones indefinidas; y la otra, bello ideal de nuestros sueños vertiginosos, feble y raquítica por el desorden de la inteligencia, por esa plétora de ilustración que, no reaccionando a favor del alma, tiene que labrar la muerte del pensamiento, ya que no por asfixia, por apoplejía (22-5-1864, p. 8).

Curiosamente, el redactor no deja también de aludir metafóricamente a la bella «fantasmagoría» en que aparecen convertidas «las figuras de nuestros mayores», como años atrás El Jorobado se refiriera a la «fantasmagoría anarquista» (19-7-1836). Así, parece evidente que el estereóscopo, como antes el daguerrotipo o el panorama y, casi al mismo tiempo que el caleidoscopio ${ }^{12}$, se convierte en nuevo símil, o metáfora, indistintamente de juguete, instrumento de análisis racional o moral, vista o estampa.

De lo que no estoy tan segura es de que, en las fechas en que he centrado este trabajo, el estereóscopo sea visto siempre como «paradigma de lo ilusorio» por el hecho de que ofreciera una imagen en relieve que no se correspondía con la realidad (Fernández 2006, pág. 321). Por el contrario, creo que buena parte de los observadores, espectadores y, quizás en mayor medida, la mayor parte de los lectores, no se plantean tales implicaciones. Que el estereóscopo les devolviera una imagen, previamente diseñada, que no se correspondía con el objeto que representaba, les resultaba indiferente. Lo relevante, según parecen atestiguar los textos que he reseñado, es que esta reconstrucción en planos superpuestos les producía una «ilusión de verdad», resultante, precisamente, de su efecto de relieve.

Si la visión binocular no parecía inquietante, tampoco la multiplicidad imaginativa del caleidoscopio supone, al menos en estas fechas, ningún conflicto en el lector-espectador. Al contrario, este, como Baudelaire, queda seducido por la multiplicidad de las imágenes que ofrece y por sus posibilidades de convertirse en conciencia de la modernidad, justo lo contrario de lo que verían en él Marx y Engels, un producto de diseño industrial que, en vez de producir imágenes nuevas, repetía mecánicamente siempre las mismas (Crary p. 152).

12. De esta invención de Brewster asegura El Imparcial (20-2-1868), que se trata de un «juguete que tantos servicios presta a los dibujantes». Por su parte, el crítico de la Revista Hispano-Americana encargado de ilustrar la figura del poeta cubano Carlos Navarrete, dice haberlo presentado como «amante, esposo, padre, ciudadano, filósofo, sus composiciones, como los vidrios de un kaleidoscopo, nos le retratan bajo todos estos aspectos.» (Revista Hispano-Americana, 15-2-1867, p. 106) 


\section{Conclusión}

El progresivo fin de la credibilidad de la cámara oscura como instrumento de captación de la realidad objetiva explica que la pluralidad y diversidad de instrumentos ópticos, con que se intenta reemplazarla, y la novedad de los espectáculos basados en su uso como medio de conocimiento, diversión o fuente de placer estético, fuera uno de los objetos de atención frecuente de la época, hasta el punto de inspirar los títulos de las cabeceras de algunos de ellos. Lo que más interesa de cada nuevo instrumento en un principio es su capacidad de proyectar una imagen lo más verdadera posible de la realidad, pero a lo largo del siglo se produce el desplazamiento desde el interés científico al mero disfrute estético. Más tarde, su paulatina generalización y normalización termina por provocar el desplazamiento del observador, su dislocación y la regulación de su conducta, contribuyendo a convertirlo en consumidor pasivo, mero espectador, de la nueva cultura visual que irá invadiendo las noticias de los periódicos.

Como apuntaba al comienzo, la retórica de los redactores que informan y reseñan los espectáculos visuales, particularmente en la prensa ilustrada y pintoresca, constituye a veces el primer acercamiento a este tipo de espectáculos. De ella dependerá no ya el interés del lector por participar en esas nuevas experiencias, sino que probablemente condicionará de algún modo esa primera práctica; pero también es cierto que, con el tiempo, esas reseñas de espectáculos van perdiendo espacio y pronto empiezan a ser sustituidas por anuncios más o menos reiterativos que insisten, sobre todo, en las novedades del espectáculo o en su «efecto sorprendente». De modo que si la metamorfosis del observador en mero espectador era poco discutida o cuestionada en los periódicos que he analizado, en el momento en que el comentario es reemplazado por el anuncio, se generaliza una información acrítica que, en todo caso, presenta la sucesión de estos nuevos espectáculos como efecto y producto de la celeridad propia de la modernidad.

Hay que tener en cuenta, además, que algunas de estas publicaciones dirigen su mirada al pasado con cierta predilección. El Observatorio pintoresco es uno de esos periódicos en que pueden encontrarse descripciones de las costumbres, de las diversiones públicas, que remiten a usos medievales bastante nostálgicas, por cierto, como la «De las romerías, danzas populares y bailes dominicales de los vascongados» (30-10-1837)_, con mucha mayor facilidad que la reseña de los modos de esparcimiento de sus coetáneos, pues sus diversiones, asegura el redactor, «se han hecho menos sencillas y más estudiadas». Esa mirada llena de melancolía no es infrecuente en otros textos costumbristas y, a pesar de que muchos, como Mesonero Romanos, aciertan 
a ver las fallas que descubren dispositivos como el panorama, no acaban más que por intuir una realidad paradójica, en la que quizás prefieren —ocupados como están en conformar una imagen nacional que sea asumida por los sectores medios y populares— no profundizar (Riego 2001, págs.114-127).

Por eso mismo, los instrumentos que podían ser más inquietantes y tal vez encerrar mayor capacidad subversiva, como el estereoscopio o el caleidoscopio, tampoco parecen destruir el efecto de realidad, la ilusión de verdad, en el espectador y, mucho menos, en el lector. Es más, diríase que la literatura periódica de los años que he examinado contribuye una y otra vez a disolver esa posibilidad, al ensalzar precisamente la modernidad que encierran estas novedades ópticas y con ello reclamar su normalidad. Conclusión provisional que conviene contrastar con un estudio más amplio de los periódicos de la época.

\section{Bibliografía}

CARABias Álvaro, Mónica. 1996, «Literatura e imagen en El Escorial», Francisco Javier Campos y Fernández de Sevilla (coords.). Actas del Simposium (1/4-IX1996) págs. 969-982

CRARY, Jonathan 2008. Las técnicas del observador: visión y modernidad en el siglo XIX, Murcia, CENDEAC.

FERNÁNDEZ, Luis Miguel. 2006. Tecnología, espectáculo, literatura. Dispositivos ópticos en las letras españolas de los siglos XVIII y XIX, Santiago de Compostela, Universidad.

FRUTOS EstebAn, Francisco Javier. 2010. Los ecos de una lámpara maravillosa: la linterna mágica en su contexto mediático. Salamanca, Universidad.

Garófano, Rafael. 2007, Los espectáculos visuales del siglo XIX. El Pre-Cine en Cádiz, Cádiz, Quorum editores.

LlORET ESQUERDO, Jaume, César Omar García Juliá y Ángel Casado Garretas. 2000. «Documenta títeres 1». Edición digital: Alicante: Biblioteca Virtual Miguel de Cervantes.

RIEGO, Bernardo. 2001. La construcción social de la realidad a través de la fotografía y el grabado informativo en la España del siglo XIX. Santander. Universidad de Cantabria.

ROMERO TOBAR, Leonardo. 1994. Panorama crítico del Romanticismo Español, Madrid, Castalia.

Rubio CRemades, Enrique. 2000. Periodismo y literatura: Ramón de Mesonero Romanos y el «Semanario Pintoresco Español». Alicante, Universidad de Alicante.

Rubio CREMADES, Enrique. 2005. «Recuerdos de viaje por Francia y Bélgica en 1840 y 1841, de Ramón de Mesonero Romanos», Edición digital: Alicante: Biblioteca Virtual Miguel de Cervantes.

Anales, 25, 2013, pp. 105-130 
SeRRERA, Juan Miguel. «Goya, Los caprichos y el teatro de sombras chinescas», en Caprichos de Francisco de Goya. Una aproximación y tres estudios. Madrid, Real Academia de San Fernando, págs. 83-112.

VAREY, John.1972. Los titeres y otras diversiones populares de Madrid, 1758-1840: estudio y documentos. London. Tamesis Books Limited.

Vega, Jesusa. 2010. Ciencia, Arte e Ilustración en la España Ilustrada, Madrid, CSIC.

Villanueva, Darío. 1992. Teorías del realismo literario. Madrid, Instituto de España / Espasa Calpe.

Fecha de recepción: 07/04/2013

Fecha de aceptación: 02/09/2013 